\title{
EL CARÁCTER NORMATIVO DEL ESTADO SOCIAL DE DERECHO EN COLOMBIA
}

\author{
DIANA PATRICIA QUINTERO MOSQUERA
}

One of the fundamental principles of the Colombian Constitution defines Colombia as a social state (Estado Social de Derecho). This principle has not been very effective, however, which threatens its existence as a norm that is binding to citizens, lawmakers, and judges. The article answers the main objections that have been made to the principle from the perspectives of economic efficiency and individual liberty and autonomy. It shows how these objections are founded on very narrow conceptions of individuals and individual rights, and of social relations and objectives. It proposes to contextualize moral reasons, so that they can justify the State's commitment to the «minimums to live» (mínimos vitales) that are part of the social, economic, and cultural rights of the Constitution.

Aquellas comunidades políticas que se definieron en sus cartas constitucionales como «Estado social de derecho» respondían al reto de ligar el imperio de la ley con la protección a las libertades individuales y la disminución de las desigualdades sociales ${ }^{1}$. Entre estas comunidades se encuentra Colombia, país en el cual el principio constitucional de Estado social no logra tener aquel mínimo de eficacia indispensable para su validez - existencia - jurídica y política. Este fenómeno puede explicarse mediante razones económicas - la pobreza generalizada, el déficit fiscal, etc. -; políticas la ausencia de un acuerdo amplio sobre los fines y tareas que deben asignarse al Estado, el conflicto armado, etc; - y/o jurídicas - el carácter enunciativo otorgado al principio de Estado social lo despoja del valor normativo que pudie-

\footnotetext{
${ }^{1}$ El Estado social de derecho puede definirse como un Estado moderno que conserva los elementos básicos del Estado de derecho, pero se desprende de su neutralidad moral, y se compromete con una noción de justicia fundada en derechos sociales
} 
sen darle legisladores y jueces de la República. Todas estas razones suelen esgrimirse en los debates sobre las posibilidades del Estado de proponerse como fin la justicia social. Pero si se toma en serio el carácter programático de la Constitución Política, la cuestión puede plantearse de otra forma: ipor cuáles razones debería el Estado intervenir en la economía para lograr algún fin social deseable, como la justicia social? ¿Por qué se deberían reconocer a los ciudadanos derechos sociales, económicos y culturales, en medio de un contexto global de adelgazamiento de la burocracia estatal?

Quienes han dirigido la economía en Colombia durante la última década no parecen darle un papel muy importante al compromiso con la justicia social, o con algún otro fin ético. La eficiencia económica ha sido defendida en forma vehemente no solo en la planeación económica, sino también frente a decisiones judiciales con efectos redistributivos. De otro lado, la prioridad de la autonomía y libertad individuales parece excluir cualquier redistribución de la riqueza a favor de los sectores más deprimidos de la población.

Considero que la importancia de estas cuestiones pone de manifiesto la necesidad de recordar la enseñanza aristotélica, según la cual la economía y la política tienen un vínculo con la ética que no es conveniente desatender. Partiendo de esta convicción me propongo presentar las objeciones más comunes que se formulan al Estado social de derecho, desde la confianza en el libre mercado, una concepción ética liberal-individualista y una valoración de sus presuntas consecuencias. A modo de respuesta a tales objeciones, formularé razones éticas que justifiquen la existencia jurídica del Estado social de derecho, en contextos de precariedad de la vida material de los ciudadanos.

Un antecedente y momento esencial del Estado social de derecho es el Estado de derecho. En este el individuo - la particularidad - se erige en el centro de la vida política y social; su plena realización o autodespliegue es el fin último de las agendas políticas. El principio de legalidad y sus valores fundantes - libertad, igualdad y seguridad jurídicas - logran limitar el ejercicio de la autoridad que tiene el poder político sobre los individuos. El lugar central de la particularidad es hoy en día, después de la derrota del socialismo realmente existente, un hito cuyo desplome no parece estar a la vista. Las teorías éticas que buscan dar cuenta de su importancia en las relaciones sociales tienen más fuerza hoy que hace un siglo. Este hecho indica la importancia de tomar en serio las objeciones más fuertes al Estado social, que se formularon hace algunas décadas, por una corriente de defensores de la particularidad, denominados «libertarios». Para Robert Nozick, uno de sus más destacados exponentes, la justicia distributiva requiere la violación de los derechos básicos de las personas, la apropiación del trabajo de otros y en consecuencia, el paso de la «propiedad sobre uno mismo» al «derecho de copropiedad sobre otros». 
La invalidez ética de este tránsito es evidente, desde una concepción atomista e individualista de las relaciones sociales.

Frederik Hayek por su parte, considera el Estado social como una perversión de la clara noción de «Estado de derecho». A su juicio, solo la igualdad ante la ley es compatible con la libertad, lo que invalida el recurso a la coerción estatal como forma de alcanzar la igualdad real en la sociedad.

Según Hospers, el Estado o los particulares que realizan prácticas compensatorias entre individuos se comportan como caníbales morales, en tanto desconocen la autonomía moral individual y violan restricciones morales básicas impuestas por la prioridad del derecho de propiedad.

De estas perspectivas se pueden extraer tres premisas básicas del pensamiento libertario, que juegan un papel destacado en el planteamiento del debate:

a. La prioridad de la autonomía moral deslegitima la coerción del Estado y el paternalismo como mecanismos para la redistribución.

b. La justicia distributiva es incompatible con la autonomía y libertad individuales.

c. Solo la igualdad formal puede establecerse sin vulnerar las libertades básicas de los individuos.

\section{Límites de la confianza liberal en el libre mercado.}

La defensa de la libertad y autonomía individuales, llevada a cabo por los libertarios, supone una gran confianza en las potencialidades del mercado para incrementar la riqueza global de la nación. Al mismo tiempo, según los libertarios, el consumo de los individuos que disfrutan de mayor bienestar material posibilita una «redistribución hacia abajo», capaz de garantizar el acceso de todos los individuos - en tanto sujetos de necesidades - a los bienes materiales básicos para la subsistencia. La autosuficiencia del mercado y una definición individualista de la comunidad política justifican la indistinción entre Estado y Sociedad. Pero la insuficiencia del mercado para garantizar a todos los individuos el acceso a los bienes materiales mínimos es un argumento fuerte a favor de un Estado corrector de los desequilibrios presentes en la Sociedad. Además, aunque en el ámbito social pueda justificarse la definición de las personas como individuos, en el espacio político o estatal esas mismas personas operan como ciudadanos. La existencia de múltiples dimensiones de las personas pone de manifiesto otro límite de la indistinción señalada.

La separación entre Estado y Sociedad, concebida como esencial por los defensores de la autonomía individual, es una falacia que se remonta a las primeras definiciones de la comunidad política como sumatoria de individuos, vinculados entre sí solo mediante procesos mercantiles para la satisfacción de sus propias necesidades. Se trata de una forma de enfrentar la cuestión 
propia de los siglos XVI y XVII, que encuentra un sustento en las teorías políticas de Hobbes, Kant y Locke, y en las tesis económicas de Adam Smith. Esta perspectiva pervive en las críticas libertarias aludidas y en ella las posibilidades y restricciones que operan en las relaciones entre individuos se extienden a las relaciones entre los individuos y el Estado. La versión económica, por su parte, cuenta con una ventaja sobre la política: constituye un anticipo del ideal moderno de distribución más equitativa de bienes y beneficios sociales. Si bien en la Riqueza de las naciones Smith considera a la mano invisible como el mejor «mecanismo» para incrementar la riqueza total de la nación ${ }^{2}$, en su Teoría de los sentimientos morales se amplía dicha metáfora: esa misma mano redistribuye la riqueza entre los distintos sectores de la población ${ }^{3}$. No basta con incrementar los bienes materiales mediante la búsqueda del propio interés, se requiere además del mercado. Este mecanismo extiende el acceso a tales bienes, hasta abarcar a los miembros más desprotegidos de la Sociedad. Smith confía en el mercado y al mismo tiempo es sensible a sus efectos negativos, por ejemplo, el empobrecimiento espiritual que puede generar en los trabajadores la rutina empresarial ${ }^{4}$.

En las orillas del liberalismo político tardarán un par de siglos más en aparecer las preocupaciones por formas de redistribución de la riqueza en la nación, o por las consecuencias nocivas que trae el mercado a la vida moral o material de los miembros de la Sociedad. Fue necesario esperar las objeciones planteadas al pensamiento liberal por parte de autores de gran relevancia como Hegel. Uno de los aportes de Hegel al pensamiento político fue la distinción entre los ámbitos del Estado y de la Sociedad. Distinguir no significaba para él separar, sino entender que estos ámbitos deben ser comprendidos cada uno en su propia lógica. Mientras la Sociedad, denominada por Hegel sociedad civil, es el ámbito de los intereses privados y egoístas, el Estado se caracteriza por el predominio del interés común o general. Los intereses particulares, como la preservación de la vida, la propiedad, la paz, y la seguridad, no posibilitan la construcción de lazos fuertes, ni aseguran el logro de la convivencia pacífica entre las distintas particularidades. A pesar de esta separación inicial, en la sociedad civil existen los estamentos: formas de asociación cuya razón de ser es la defensa de los intereses de cuerpo, o la sumatoria de los intereses particulares que lo conforman. Cada particularidad busca de manera legítima la forma de proveer su propia existencia material y al hacerlo contribuye, sin proponérselo, a la satisfacción de las necesidades materiales de otras particularidades.

${ }^{2}$ Smith, Adam, Investigación sobre la naturaleza y causa de la riqueza de las naciones, F.C.E., México

D.F., 1994, p. 402.

${ }^{3}$ Smith, Adam, ob.cit. ( 1), p. 333.

${ }^{4}$ Sennett, Richard, La corrosión del carácter, Anagrama, Barcelona, 2000, pp. 37 a 39. 
En la persecución de los fines individuales se realizan fines universales, de manera indirecta e inconsciente ${ }^{5}$. Sin duda en este punto Hegel comparte la perspectiva de Smith, pues afirma la existencia de mecanismos redistribuidores de riqueza, que actúan con independencia de una relación consciente entre la voluntad y el universal que se alcanza. El distanciamiento entre ambos opera en cuanto al establecimiento de controles a la actividad particular, en el marco de la sociedad civil. Para Hegel el egoísmo extremo propio de dicha esfera impone la necesidad de una fuerza exterior encargada de dirigir las actividades productivas, para asegurar a las personas más vulnerables o socialmente desfavorecidas la participación en la riqueza global ${ }^{6}$. Para Smith, en cambio, es más adecuado eximir al soberano del papel de vigilar y dirigir la actividad particular, labor que sólo puede realizar bien la divinidad. La dirección de la actividad económica no debe ser, según el padre de la economía, una labor política.

Hegel valora el ámbito de la particularidad tanto como Smith, y reconoce el derecho de los individuos a trabajar y luchar por la satisfacción de sus intereses. Sin embargo, descubre en el juego de intereses egoístas contradicciones que la sociedad civil es incapaz de superar, de allí la necesidad de acudir a una instancia ontológicamente superior: el Estado. Las contradicciones obedecen a múltiples factores, pero resulta significativo el lugar que ocupan la miseria material y moral en que se ven sumidos sectores importantes de la sociedad civil, como consecuencia de dejar al libre juego del mercado la satisfacción de las necesidades particulares. Los límites de la esfera de la particularidad o de la instancia de la moralidad justifican, en parte, el paso hacia el ámbito estatal que es, según Hegel, el de la eticidad?

Si se dejan de lado los aspectos del pensamiento hegeliano que sus críticos consideran totalitarios, se puede reconocer la contribución hegeliana al tema de los límites de la sociedad civil. Su afirmación sobre el rol egoísta que cada uno de los individuos juega en dicha sociedad es precursora de una tradición crítica del libre mercado.

Hoy en día se reconoce que la indiferencia liberal hacia la situación de marginalidad económica, social y cultural de la mayoría de los miembros de la sociedad resulta anacrónica: surgió en un contexto de nacimiento del capitalismo industrial y no durante su crisis. Hay una profundización de esta crisis, lo que se evidencia, en parte, en la inseguridad global que aqueja tanto a sociedades

\footnotetext{
${ }^{5}$ Hegel, George W.F., Fundamentos de la Filosofía del Derecho, Siglo Veinte Editores, Buenos Aires, 1987, pp. 192 a 201.

${ }^{6}$ Hegel, George W.F., ibid., pp. 214 a 221.

${ }^{7}$ Ver Hegel, ibid., pp. 218 y 219. En los parágrafos 243 y 244 Hegel deja entrever cierta desazón por la creciente pauperización de algunas capas de la población ( plebe ), que se dan a la par con la acumulación de riqueza de otro sector (burguesía).
} 
periféricas como centrales. El terrorismo, la proliferación de delitos financieros, la inestabilidad jurídica, el desempleo, entre otros, son fenómenos que probarían esta hipótesis. La extensión de la marginalidad tarde o temprano deslegitima las instituciones, corroe los lazos que forman la nación y afecta la seguridad y paz de todos, llámense individuos o Estados.

Los resultados de miseria que trae el libre juego del mercado imponen la necesidad moral de superar la percepción de la Sociedad como un simple «sistema de necesidades»; lo que no excluye considerarla también como tal. Una visión más amplia pasa por el reconocimiento de los aportes hechos por la tradición liberal clásica a la explicación de las relaciones sociales y a la asignación de tareas y restricciones al cuerpo político. Parte fundamental de dicho legado son las nociones de libertad y autonomía en su sentido negativo: como ausencia de restricciones externas a la búsqueda y realización de un ideal particular de vida buena.

\section{El carácter formal o abstracto de una libertad desligada de las condiciones materiales para su realización.}

En un Estado social de derecho la libertad jurídica de los individuos es posible por la constitucionalización y realización efectiva de una serie de libertades fundamentales, conocidas como derechos civiles y políticos. Pero la consagración positiva de estos derechos es compatible con una libertad individual puramente formal. Los defensores del libertarismo reducen la «libertad» a la libertad negativa, ignorando la amplitud que la noción genérica ha ganado a lo largo de la historia. Los primeros reclamos por libertad en la sociedad moderna, fueron formulados contra las pretensiones de los demás individuos y del Estado de controlar la totalidad de la vida individual. Se buscaba que el individuo pudiese disfrutar de un espacio o ámbito sin coerción externa, para trazar libremente su proyecto de vida y que tuviese la posibilidad de realizarlo, en el marco del respeto a los proyectos de vida de los demás. Una vez alcanzado este ideal se creyó que esa ausencia de restricciones externas era suficiente para la consecución del ideal de vida buena. Sin embargo, la conquista de la libertad individual frente a la coerción externa no ha logrado evitar ni reducir la pobreza, en especial aquella que resulta paralizante para los individuos de amplios sectores de la Sociedad.

El sentido negativo de la libertad es propio de una visión del mundo que valora la posibilidad de escoger el propio proyecto de vida, sin atender a la posibilidad material de realizarlo. Se trata de una concepción sustancialmente no solidaria, poco o nada sensible a las carencias ajenas, e indiferente frente al hecho de que la mayoría de individuos no dispongan de posibilidades reales para alcanzar los fines escogidos, o para gozar de los derechos y libertades básicas. Los derechos a la vida y a la igualdad, la libertad de escoger profesión u oficio y demás libertades que se consideran fundamentales, no tienen validez si el individuo carece de la posibilidad de gozar de ellos por la ausencia de los medios materiales básicos.

\section{RREGCFDENTE}


El carácter abstracto de los derechos contrasta con la realidad de marginalidad social, económica, política y cultural en que se desenvuelven la mayoría de individuos en la Sociedad. La poca eficacia política y jurídica de los derechos y libertades pone en peligro su validez ética. ¿Por qué no tendría más sentido hablar de objetivos sociales como la eliminación de la pobreza, que hablar de derechos y libertades? De esta forma se lograría un despliegue de acciones políticamente efectivas, a favor de los más vulnerables social, económica y culturalmente. Las acciones políticas podrían a su vez dar cuenta de la transformación del valor de los derechos, producida por los cambios sociales $^{8}$.

La cuestión del supuesto carácter abstracto de los derechos y la mayor efectividad de las acciones políticas es valiosa. Mediante ella se pone de relieve la insuficiencia de pretender asegurar las demandas individuales de libertades con la consagración formal de un listado de derechos de supuesta validez universal. Estos reparos no tienen la fuerza para cuestionar la vigencia e importancia de los derechos humanos. De ellos se desprende simplemente la necesidad de que la dimensión ética y jurídica de los derechos se articule de manera orgánica con una dimensión política que les dé alcance real y los convierta en instrumentos de inclusión social. Se logra el mismo cometido mediante la inclusión de la realidad social en la esfera jurídica: la validez de un derecho no derivaría de su consagración formal, sino de su realización efectiva. Desde esta perspectiva, el carácter jurídico de un derecho garantizaría su existencia real, lo que necesita una fundamentación ética anclada en la realidad cultural, política y social de los individuos titulares de los derechos.

En lugar de ensayar una fundamentación universal que apele a la razón o a los sentimientos humanos como rasgos propios de la especie humana, ciertos derechos quedan mejor sustentados en las necesidades espirituales y materiales de una cultura determinada. Un derecho sería moral si consulta las peculiaridades de dicha cultura. La denuncia del carácter inestable de los derechos ilustra las dificultades de sustentar las relaciones sociales en valores morales ahistóricos y atemporales como los derechos?.

\footnotetext{
${ }^{8}$ Ver Tushnet, Mark, pp. 141-142. Esta línea argumentativa es seguida por filósofos políticos y jurídicos denominados realistas. Uno de ellos, Mark Tushnet, considera los derechos como abstractos e inestables. A su juicio, el discurso de los derechos no logra dar cuenta de las peculiaridades culturales de sus sujetos titulares, ni permite la realización de las medidas políticas necesarias para mejorar las condiciones de vida de los ciudadanos. Para probar su hipótesis, Tushnet cita ejemplos tomados de la realidad norteamericana en los cuales no parece tener sentido hablar en términos de derechos, sino de fenómenos sociales cuya atención requiere el concurso del Estado. ${ }^{9}$ Tushnet tiene razón al afirmar que el valor de los «derechos» es relativo a la realidad en que se desenvuelven los titulares de los mismos. Su existencia y pertinencia dependen de los reclamos que en la esfera política resulten más sentidos, en un momento histórico determinado.
} 
Los derechos son creación social e histórica; en determinadas circunstancias logran entrañar una pretensión de estabilidad, al establecerse mediante procesos sociales de lucha por su reconocimiento. Tienen un status normativo: no sólo reflejan una realidad social dada, sino también las aspiraciones de quienes aseguran el apoyo político de algún sector de la población. Aunque en principio ese sector se refiere a las mayorías, las voces de las minorías con alguna representatividad son atendidas, mediante el establecimiento de normas que establecen cambios en las condiciones de marginalidad en que viven sus miembros. En un panorama político de inclusión real, los derechos morales llegan a ser reconocidos como derechos jurídicos. Su carácter moral derivará de la necesidad con que se imponen para determinados sectores sociales. Los derechos consagrados positivamente constituyen la expresión de una aspiración válida, anclada en el reconocimiento de los sujetos de necesidades.

Las críticas a los derechos, formuladas desde el realismo, ponen en entredicho su pretensión de universalidad y el establecimiento de un catálogo único de derechos válidos para cualquier contexto. Si se toma en serio esta objeción, es posible afirmar que los derechos son facultades individuales o colectivas - ejercidas en un determinado contexto social, económico y cultural - que reflejan a su vez las características o aspiraciones más sentidas por las personas en una coyuntura cultural o histórica. No son universales en sentido real, aunque conlleven una pretensión de universalidad. En este orden de ideas se les presta un mejor servicio si la definición de su sentido, alcance y justificación ética toman en consideración las circunstancias materiales y espirituales de sus titulares.

El desconocimiento del carácter históricamente - determinado de los derechos puede traer como consecuencia el formalismo o existencia formal de libertades que no logran realizarse en ausencia de condiciones materiales adecuadas. La percepción de los derechos como una «retórica» que sirve por igual a cualquier interés político, o la posibilidad de que ellos convivan con la ausencia de libertades reales de una parte importante de la población, acaban por quitarle valor a la libertad jurídica y a los derechos que la realizan. El carácter formal de las libertades generalmente sirve a la justificación de actitudes nihilistas frente a los derechos, que resultan más perjudiciales en contextos donde no hay una cultura de civilidad consolidada. El espíritu de intolerancia, de desconocimiento del otro en su peculiaridad y de indiferencia frente a la pobreza material, es quizás la causa y al mismo tiempo el resultado de la negación del valor de las libertades individuales. Este círculo vicioso sólo puede romperse con otras formas de entender la libertad, que el Estado debe respetar y a su vez contribuir a consolidar, a fin de hacer real el disfrute de las libertades formalmente consagradas. La sociedad civil, como espacio de la particularidad, no logra resolver por sí misma este problema y en su fracaso impone al Estado la tarea de «debilitar los puntos débiles de dicho círculo vicioso», para usar una expresión de Macpherson ${ }^{10}$.

${ }^{10}$ Ver Macpherson, C.B., La democracia liberal y suépoca, Alianza, Madrid, 1982, p. 123. 
Se objetará que ir más allá de la visión formalista de los derechos significa ampliar excesivamente el ámbito de la solidaridad humana: se abandonaría la tesis liberal de la «separabilidad» de los individuos y la prohibición de utilizar el aparato estatal para corregir las falencias del mercado ${ }^{11}$. Pero desde las propias orillas del liberalismo se han concretado críticas en el sentido señalado. Filósofos como el estadounidense Richard Rorty consideran posible la existencia de relaciones solidarias entre los individuos, que no impliquen una pérdida de autonomía o libertad personal. Para Rorty la obligación moral de solidaridad no debería fundarse en una concepción esencialista de la naturaleza humana, y debería afianzarse por medio de una adecuada educación de los sentimientos. Rorty insiste en la necesidad de ir ensanchando de manera paulatina el círculo de un «nosotros», para incluir allí - como objeto de obligaciones solidarias - no solamente a los miembros de la familia y a los amigos, sino también a personas aparentemente lejanas y extrañas, con quienes compartimos problemas comunes de la condición humana. De esta forma el individuo llegaría a identificarse con el dolor y la humillación padecidos por los sujetos originariamente excluidos de la solidaridad parental. Esta ampliación del ámbito de la solidaridad humana constituiría un verdadero progreso moral $^{12}$.

Las perspectivas liberales no libertarias como la de Rorty pueden resultar más adecuadas al presente momento histórico. Las grandes solidaridades cuyo referente es la nación, el Estado, el partido, etc., se han visto desplazadas por solidaridades micro, que cohesionan a las personas en torno a sus gustos y necesidades más personales. Esta constatación se encuentra también en el aporte de los llamados «posmodernos», aunque para ellos resulta impensable la confianza en el progreso moral. La ampliación de la solidaridad entendida como progreso moral no es ajena al pensamiento liberal. Desde Stuart Mill ha existido el reconocimiento de los límites del formalismo universalista kantiano. Sin una sensibilidad y educación morales mínimas, la dignidad como atributo humano esencial es una abstracción, que nada dice en contra de infringir tratos degradantes o crueles a los individuos.

Esta crítica no invalida el aporte kantiano a la fundamentación ética de los derechos. La noción moderna de «dignidad humana» se ha consolidado en Occidente como un importante sustento de las obligaciones morales que tenemos hacia las demás personas. Sin embargo, la crítica pone de manifiesto una de sus limitaciones más sentidas, sobre todo en contextos de profunda miseria moral, en donde la dignidad de las personas es constantemente desconocida o pisoteada. Sin una educación racional no se logra el cometido de extender el reconocimien-

\footnotetext{
${ }^{11}$ Vázquez, Rodolfo, Liberalismo, Estado de derecho y minorías, Paidós, México D.F., 2001, pp. 50 y 53.

${ }^{12}$ Rorty, Richard, Contingency, irony, and solidarity, Cambridge University Press, Cambridge, 1989, pp. 189 a 193.
} 
to de la dignidad intrínseca del ser humano, de la misma manera que sin una educación sentimental no se logra el propósito de ampliar la esfera de ese «nosotros» que menciona Rorty.

La modificación de la solidaridad liberal sólo es posible si se acepta que los individuos cuentan con otras formas de realizar su libertad, distintas a la ausencia de restricciones externas. En la actualidad se sostiene la existencia de otras formas de entender la libertad genérica, no sólo en el ámbito de la filosofía moral o ética, sino también en el de la economía. El economista Amartya Sen distingue entre la libertad formal y la libertad sustancial. Ésta es definida como la capacidad de funcionamiento, que garantiza a los individuos la posibilidad de vivir la vida que consideran valiosa ${ }^{13}$.

La libertad como capacidad ha sido un legado fundamental de la tradición socialista al tema, que en ocasiones es recogida en las formulaciones de los pensadores liberales más progresistas. Se refiere a la opción real de los individuos de escoger entre distintas formas de vida, y supone unas condiciones materiales de vida que liberen al individuo de la zozobra por adquirir los bienes de subsistencia más básicos y le permitan ampliar la esfera de sus necesidades. Algunos filósofos consideran que el enfoque sobre las capacidades es una contribución liberal al tema de la libertad, porque se trata de una noción autorreferente, que no requiere la intervención de una instancia externa al propio sujeto. La capacidad sería entendida como «aquello que puede hacer la persona» por sí misma ${ }^{14}$, y no aquello que los demás - Estado o Sociedad - pueden hacer por ella. Sin embargo, las condiciones materiales de vida no siempre quedan garantizadas con el concurso de la voluntad individual. Hay factores externos de naturaleza física - discapacidades - o social - marginalidad cultural - que pueden erigirse en obstáculo para el acceso a una capacidad autorreferida. Los problemas de desnutrición, por ejemplo, no pueden achacarse a la falta de previsión o de voluntad, en aquellas culturas en las cuales la paternidad y la maternidad tempranas son condición para la aceptación y reconocimiento social.

La noción «libertad» también puede comprender la participación efectiva en las decisiones políticas que se dan en el marco de una comunidad ${ }^{15}$. Tanto la libertad

\footnotetext{
${ }^{13}$ Sen, Amartya, Desarrollo y libertad, Ed. Planeta, Bogotá 2000, p. 350.

${ }^{14}$ Vázquez, Rodolfo, pp. 39 y 40.

${ }^{15}$ Ver Hegel ob.cit., pp. 77 a 84. En la Introducción a la Filosofía del Derecho, Hegel hace una genealogía de la idea moderna de libertad y formula una crítica a cada una de las formas que reviste: la libertad como indeterminación es propia de una voluntad pura no comprometida con algún objeto que le sirva de contenido, la libertad como desahogo de los impulsos es la búsqueda ilimitada de la satisfacción de los propios impulsos e instintos, la libertad como albedrío es la persecución arbitraria e infinita de distintos bienes y la libertad como atomización o separación individual, que coincidiría con la libertad negativa descrita por I. Berlin. El aporte valioso de Hegel es la crítica que ejerce sobre cada una de estas nociones a fin de mostrar su carácter unilateral, parcial y por tanto limitado.
} 
positiva como la libertad política son hoy en día parte integral de la libertad jurídica, interpretada en su sentido no formalista. Por otra parte, la libertad política no es una forma de libertad ajena a lo que significa ser libre en el marco de una sociedad democrática. La participación en las decisiones colectivas no puede reducirse a la libertad de las «cadenas» que imponen los otros o el Estado; ella se realiza mediante la acción política. Desde un punto de vista ético la acción puede válidamente considerarse como un rasgo propio del ser humano. Es la acción praxis - la que determina la posibilidad del juicio moral, al tiempo que se constituye en expresión de libertad. La libertad como participación o acción política se erige en elemento básico de la vida social y política moderna. Los denominados derechos políticos constituyen en la democracia actual un conjunto de facultades y obligaciones, consideradas como un legado irrenunciable de la modernidad. El Estado democrático moderno supone individuos dotados de potestades que les permitan participar en la toma de las decisiones que les atañen, en tanto miembros de una comunidad política. Supone a su vez que dichos individuos conocen el contenido de las obligaciones correlativas a sus facultades políticas.

La reducción de la acción política a la elección de los miembros del Parlamento o del Poder Ejecutivo no se compadece con la ilegitimidad que a menudo despliegan estos poderes públicos. El carácter poco ilustrado de los miembros de la comunidad política es aún hoy un problema real de la democracia, que no logra por ello desvirtuar la fuerza de las demandas por una mayor democratización de la vida pública. El ámbito del Estado, elemento central de dicha vida, no es ajeno a tales demandas. El deseo de mayor democratización ha llevado a su vez a la creación de organizaciones sociales y políticas que propenden por la superación de los límites de la acción política individual, en cuanto a su formación y posibilidades materiales de acción ${ }^{16}$. Tales formas organizativas canalizan el deseo de expresión individual, y posibilitan el ejercicio material de las libertades ligadas a la participación: la libertad de expresión y opinión política, de elegir y ser elegido, de fundar partidos y asociaciones políticas, de ejercer la oposición democrática, etc. La libertad política es, en suma, una libertad de acción individual y colectiva, en un contexto político democrático. Es esta realidad lo que lleva a Ernst Forsthoff a afirmar que «en el Estado social de derecho las garantías jurídico-sociales no son limitaciones sino participación ${ }^{{ }^{17}}$.

Aunque la libertad negativa no agote la noción de libertad, es necesario reconocer su valor histórico para la realización de las vidas individuales y para el me-

\footnotetext{
${ }^{16}$ Es necesario señalar que la exigencia de mayor democratización se desvirtúa cuando se extiende a ámbitos como el familiar o escolar, porque en ellos la lógica de las relaciones sociales presentes torna insuficiente el recurso al lenguaje de los derechos. Estos no logran dar cuenta de la totalidad de estas relaciones.

${ }^{17}$ Ver Forsthoff, Ernst y Doehring, Karl, pp. 191 a 200.
} 
joramiento de las relaciones entre el Estado y el individuo. La imposición de restricciones al cuerpo político y social para resguardar un ámbito individual, es un aspecto fundamental de la sociedad democrática actual.

Los autores provenientes de la tradición liberal mencionados en este escrito conciben la autonomía en sentido negativo: como ausencia de interferencia para elegir entre distintas preferencias y deseos. Esta perspectiva impone a los demás individuos y al Estado un deber de respeto a la capacidad de elección individual, al margen del valor moral que se asigne a su contenido. La crítica al liberalismo nuevamente denuncia, en esta forma de concebir la autonomía, cierta indeterminación contraria al vínculo necesario entre la elección y la realización de las preferencias y los deseos. Las condiciones materiales de pobreza extrema excluyen a los individuos de la posibilidad de ser autónomos en sentido material o real. El contenido de la preferencia, por su parte, resulta relevante a la hora de determinar si se trata o no de un acto autónomo del individuo.

La indeterminación del contenido de la autonomía negativa ha propiciado propuestas orientadas a precisar mejor su contenido, y a concebirla en términos de autogobierno, autenticidad o autoconstrucción individual. Para Ronald Dworkin o Charles Taylor, por ejemplo, autonomía es la capacidad de observar el autocontrol, la coherencia y la racionalidad pragmática y ética necesarias para mirar críticamente la propia escogencia, y darle contenido moral. La autonomía así concebida supone en el individuo no solamente la destreza en la escogencia de sus fines y la persistencia del compromiso con ellos, sino también la voluntad de respetar el carácter libre y autónomo de los demás sujetos con quienes comparte la vida social. Otra forma de entender la autonomía sería aquella que la identifica con la búsqueda de la autenticidad, propia de una individualidad cultivada en la fidelidad a lo más auténtico del sujeto, en oposición a la uniformidad que genera la sociedad de masas. Finalmente, aunque relacionada con esta última, la autonomía es entendida por algunos autores como la capacidad de delinear una existencia hermosa e irrepetible ${ }^{18}$.

La autonomía «positiva», en cualquiera de sus modalidades, cumple la misión de corregir las falencias de la autonomía «negativa», dejando intactas sus partes valiosas. Nuevamente remite a la capacidad de realizar el contenido de la escogencia personal. En principio no es una capacidad «exterior», porque se trata de la posibilidad moral del individuo de realizar aquellos actos que le llevarán a concretar su escogencia. En este sentido es una capacidad autorreferida, que excluye la intromisión de los demás individuos o del Estado en el ámbito de acción individual. La autonomía así comprendida es compatible con la libertad

\footnotetext{
${ }^{18}$ Ver Papacchini, Angelo, «El porvenir de la ética. La autonomía moral, un valor imprescindible para nuestro tiempo», en Revista de estudios sociales, No. 5, Enero de 2000.
} 
negativa: si otros individuos o el Estado no constriñen al individuo, éste podrá persistir en la búsqueda de su ideal de vida valiosa de manera coherente e incluso llegar a ser auténtico en su autodespliegue.

Los críticos del libertarismo se han preguntado si resulta posible escoger los fines, persistir en su búsqueda, perseguir la autenticidad y cultivar una existencia hermosa y única, sin condiciones materiales adecuadas. El respeto por la autonomía y libertad de los demás individuos no se excluye, en principio, en un marco de pobreza material. Pero la despreocupación por la pobreza material extrema de algunos individuos no puede interpretarse como respeto a su autonomía. En el lenguaje ordinario no se utilizaría la expresión «respeto por su autonomía» para referirse a la despreocupación por una persona que no logra satisfacer sus mínimos vitales. De hecho, la expresión alude a la capacidad de dirigir la propia vida, de acuerdo a principios aceptados y reconocidos y a la capacidad económica de solventar la realización del propio proyecto vital.

A menudo se le objeta a la noción de «autonomía positiva» su vínculo con una tradición de dominación totalitaria ${ }^{19}$ sobre el individuo. Pero esta crítica descuida un hecho relevante para su comprensión: pervive en ella el respeto por el sentido que el individuo otorga a su propia vida. La idea racional de proyecto vital obliga al individuo a imponerle restricciones a aquellos rasgos suyos que lo alejan de su ideal. La «dominación» sobre sus impulsos le permite lograr una vida valiosa, en la cual se dé alcance a las metas propuestas. El autodominio es un proceso subjetivo, aunque algunos teóricos lo interpreten como la imposición del Estado o la comunidad - identificado con un «yo auténtico» - sobre el individuo. La idea de autonomía positiva impone por el contrario límites precisos a las pretensiones estatales de control sobre la vida individual. Se trata de los mismos límites que operan en contra de las pretensiones de los individuos sobre las vidas de los demás. Las restricciones a terceros excluyen, en principio cualquier forma de perfeccionismo. El Estado, como resultado del valor adquirido por la autonomía individual, debe permanecer

\footnotetext{
${ }^{19}$ Ver Berlin, Isaiah, pp. 202 a 225. Berlin rastrea en sus dos conceptos sobre libertad el surgimiento de la libertad positiva. Se trata del proceso mediante el cual el «yo» se escinde en un yo superior auténtico y en un yo inferior. El primero se identifica tradicionalmente con las esferas institucional, estatal, de clases, partidos, la voluntad general, etc. El segundo con lo individual o particular. La verdadera libertad, entendida como realización del yo verdadero, puede requerir el sacrificio del individuo mismo, en tanto yo inferior, ignorante y carente de juicio. Los fines de las partes o individuos quedan desplazados por los fines del todo: sociedad, nación, etc, en su calidad de representantes de la razón y la grandeza. El Estado virtuoso asume la capacidad de ignorar los deseos de los asociados, de intimidarlos y oprimirlos, obligándolos a asumir ciertos fines y conductas en contra de su voluntad. Lo fines estatales son tan benéficos que los propios individuos, de no ser tan incultos e ignorantes, se los habrían propuesto de forma autónoma.
} 
neutral frente a las concepciones de vida buena preferidas por los individuos. En este límite el Estado moderno encuentra uno de sus mayores retos: encontrar procedimientos políticos no demagógicos, que den cuenta de las necesidades materiales individuales sin el recurso a medidas perfeccionistas.

El dique al Estado se justifica porque el reconocimiento a la autonomía negativa es un avance histórico importante. La autonomía como ausencia de restricciones externas a la posibilidad de elegir, al igual que acontece con la libertad negativa, ha cumplido un valioso papel de freno a las pretensiones perfeccionistas de los demás individuos y del Estado sobre las vidas individuales. Ha permitido a los individuos - en mayor medida a aquellos con posibilidades materiales - una existencia rica en opciones vitales y de realización personal; ha sido también condición básica para el establecimiento de algunos derechos fundamentales.

La capacidad de escoger la vida que se considere personalmente valiosa, de participar de la vida política, de dominar las propias pasiones, de escoger los propios fines y darse las propias normas morales, de lograr la autenticidad o una existencia hermosa y única, son todas expresiones de la libertad individual. Mediante el despliegue de estas capacidades las personas pueden constituir su identidad individual, en el marco de una sociedad pluralista y democrática que imponga restricciones a las formas de dominación ejercidas en el Estado y en la Sociedad.

\section{Alcances de la igualdad formal}

La igualdad ante la ley, sumada a la libertad y la autonomía formales, completa el cuadro de valores considerados intocables por los libertarios. Aquello que no pueda derivarse de estos valores no merece el título de «derecho»; por el contrario, constituye una violación de los «verdaderos» derechos fundamentales. La igualdad logra un lugar en esta privilegiada lista, pero sólo como igualdad ante la ley, identificada con el principio según el cual la ley debe considerar a todos los ciudadanos como iguales en derechos y deberes. Cualquier otra forma de entenderla implicaría desconocer las restricciones morales básicas impuestas por los derechos - libertades a los demás individuos y al Estado.

Una de las principales críticas que se hacen a la igualdad formal recae en la función social que ha cumplido. Contra ella se afirma que sirvió y sirve con efectividad a la reproducción de las condiciones de desigualdad social y económica entre los ciudadanos. Esta perspectiva es propia de la tradición socialista, cuyos antecedentes teóricos se encuentran en las formulaciones de los socialistas utópicos y científicos. Saint-Simon o Babeuf, por ejemplo, denunciaban la falta de una repartición más equitativa y justa de la riqueza entre los 
ciudadanos, durante la revolución francesa. Para sus continuadores, los denominados «socialistas científicos» como Federico Engels, o Carlos Marx, una sociedad de ciudadanos absolutamente iguales no requiere de un aparato represivo, encargado de reproducir la dominación de las clases económicamente privilegiadas sobre las clases más desfavorecidas. Según esta última perspectiva, la igualdad no sirve de límite al ejercicio del poder en el Estado, porque el Estado mismo debe desaparecer, debido a su condición de reproductor de la desigualdad material entre los ciudadanos. La igualdad sería una facultad del «hombre burgués», es decir, de un individuo aislado de los demás miembros de la Sociedad.

Las críticas a la igualdad formal y el deseo igualitarista inspiraron algunas revoluciones socialistas, cuyos efectos prácticos de pobreza, corrupción y pérdida ciudadana de libertades individuales son los argumentos utilizados por quienes desconfían de la igualdad material como ideal político. A esto se sumó el sentido tomado por la igualdad como fin social: su carácter deseable servía de justificación a la utilización de cualquier mecanismo para lograrla, incluida la violencia. El recurso al perfeccionismo, al desconocimiento de la autonomía de quienes poseen bienes materiales y demás prácticas violatorias de las libertades fundamentales, fueron asociadas a los ideales igualitaristas. Este fenómeno inspiró la contraofensiva libertaria neoconservadora, bien representada por Nozick, Hayek y Hospers.

Un nuevo llamado a la tradición obliga a reconocer que las críticas socialistas en conjunto tienen la ventaja de demostrar las insuficiencias de la igualdad formal, establecida por las revoluciones burguesas. En concreto, han sustentado la lucha por el establecimiento de condiciones igualitarias para los trabajadores. $\mathrm{Y}$ en general abrieron la puerta a otras formas de entender la igualdad, que en la actualidad han logrado reconocimiento social y jurídico. Su valor no quedaría desvirtuado por los efectos nocivos de algunos intentos socializadores, así como las insuficiencias del liberalismo libertario no han invalidado el papel de las libertades en la construcción de una sociedad justa.

Debe reconocerse que las teorías socialistas son en general indiferentes a las condiciones de vulnerabilidad de ciertos grupos, unidos por identidades y rasgos como el género, las discapacidades o la cultura. La agencia de las mujeres, de las minorías étnicas o de las personas discapacitadas serían secundarias, frente a la tarea de lograr la igualdad real entre los trabajadores y propietarios. El aspecto valioso del aporte de estas teorías se puede sintetizar en la necesidad de alcanzar la igualdad material, como verdadera forma de emancipación individual.

En oposición a las críticas contra el ideal igualitario, se reconoce cada vez más el importante papel que desempeñan en la vida social y política otros sentidos de la igualdad, distintos a su versión formal. Estos sentidos son 
reclamados con vehemencia, desde la segunda mitad del siglo pasado, por aquellos sectores sociales inicialmente excluidos del reclamo socialista. Las demandas han tenido eco en el concierto internacional y cada vez más en las Constituciones y los aparatos administrativos de los países periféricos. La consagración de derechos sociales económicos y culturales apunta a la integración de las demandas por bienestar material con las demandas por reconocimiento. Algunos teóricos han mostrado lo absurdo de considerar estos dos ideales de justicia como excluyentes ${ }^{20}$. Es necesario reconocer que la integración social de las personas tradicionalmente excluidas de la vida colectiva depende del establecimiento de condiciones materiales adecuadas, en la misma medida en que depende de la existencia de condiciones de respeto (no mera tolerancia) a sus peculiaridades naturales y culturales.

Los nuevos sentidos de la igualdad han sido posibles por la amplitud misma del término, al igual que acontece con los valores de libertad y autonomía. Sin embargo, la igualdad tiene una peculiaridad que la distingue de éstos. Mientras que la libertad y la autonomía son valores sustantivos, que no requieren ningún criterio de «distribución», la igualdad debe predicarse frente a algún bien o valor socialmente valioso. En este sentido supone un criterio de distribución de ese «valor o bien». Los criterios tradicionalmente utilizados se han concretado en algunas reglas, estudiadas por los filósofos morales y políticos, mediante las cuales se establece la forma como deben distribuirse determinados beneficios o cargas entre las personas que componen la Sociedad. Solo la aplicación de estos criterios permitiría el paso de la igualdad formal a la igualdad real o material. Las siguientes reglas ilustran el sentido que toma en la actualidad, después de la crisis del socialismo real y en tiempos de crisis del capitalismo, la reivindicación igualitaria:

a. Debemos tratar a las personas de manera igual, a menos que exista una justificación razonable para tratarlas en forma desigual.

b. Debemos garantizar a las personas la posibilidad real de satisfacer sus propias necesidades materiales y espirituales.

La primera se refiere a la igualdad de trato y la segunda puede comprenderse bajo la igualdad de oportunidades. Ambas nociones de igualdad se diferencian tanto en las discusiones filosóficas como en el lenguaje ordinario. La «igualdad de oportunidades» se utiliza para referirse a la posibilidad real de acceder a una educación acorde con las propias capacidades. Por esto la educación es reconocida como una forma de modificar las condiciones iniciales para el desempeño en la vida productiva, a favor de los más

\footnotetext{
${ }^{20}$ Fraser, Nancy, «Redistribución y reconocimiento: hacia una visión integrada de justicia del género» en Revista Internacional de Filosofía Política, No. 8, Ed. UNEM y UAM, Madrid, 1996, pp. 20 a 31.
} 
desfavorecidos. Más allá de la educación, el Estado se ha comprometido paulatinamente con la procura de los mínimos vitales en conjunto, a fin de dar satisfacción a las necesidades materiales y espirituales de los miembros de la comunidad política.

La igualdad de trato involucra el derecho a obtener un igual tratamiento por parte del Estado y de los particulares, en la distribución y reconocimiento de derechos y libertades, bienes, cargas y posiciones sociales. La lista no es exhaustiva, se trata por el contrario de mínimos que permiten el despliegue de la vida individual, en condiciones acordes con la igual dignidad de las personas. Es una fórmula a través de la cual se reivindica el derecho de las personas a no padecer tratos diferenciados injustificados o arbitrarios, basados en prejuicios o criterios sospechosos. El criterio sospechoso es aquel que tradicionalmente se ha utilizado para excluir a personas y grupos de personas de ventajas sociales; entre estos se cuentan la raza, el género, la condición económica, física, política, etc. El objetivo de la norma es dejar sin sustento moral cualquier forma de discriminación, en su sentido negativo. A pesar de la distinción lingüística entre ambas nociones de igualdad - de trato y de oportunidades - en la práctica es complicado separarlas, debido a que en la primera se puede incluir el derecho a obtener un igual tratamiento en la distribución de beneficios y oportunidades, por parte del Estado.

Es importante hacer una aclaración final sobre este punto. En un Estado democrático las personas no tienen un derecho a ser admitidas en cualquier grupo o a disfrutar de determinado privilegio o trabajo, tienen derecho a ser tratadas en virtud de su reclamación, con la misma consideración y respeto con que se trataría a una persona por quien se tiene un aprecio especial. Tampoco se trata de aceptar que todas las personas deban cumplir con las mismas obligaciones sociales o económicas. El criterio utilizado es imponer más cargas a quienes tienen más beneficios sociales y menos cargas a los menos favorecidos. Las cargas impuestas a quienes tienen una mejor posición social y económica se justificarían en parte por los beneficios que derivan de vivir en sociedad; los cuales son significativamente mayores a los obtenidos por quienes solo poseen su fuerza de trabajo y su familia.

Las reglas que concretan la igualdad de trato y de oportunidades son de tipo redistributivo, porque mediante la imposición de impuestos a los que más poseen, compensan las desigualdades en riqueza, salud y talento de las personas, a favor de quienes tienen menos capacidad de seguir un plan de vida gratificante. La redistribución así planteada es compatible con la autonomía de las personas, porque persigue la maximización de la capacidad real de los individuos de disfrutar de sus libertades individuales, sin restringir en su núcleo básico la autonomía de otros individuos. No es suficiente que la Constitución y las leyes del Estado establezcan el derecho a la vida, a la libertad y a la autodeterminación, si no se cuenta con los medios materiales mínimos para el disfrute de esas libertades y derechos, es decir para llevar una vida digna de todo ser humano. 
La crítica de algunos teóricos como Nozick a estos dos «principios pautados de justicia» no tendría sentido si aceptamos que el ideal igualitario ha logrado, con igual eficacia que el ideal libertario, establecerse como aspecto central de los objetivos sociales que cualquier comunidad política tiene derecho a percibir como valiosos en la actualidad. Si los derechos tienen sentido, no como rasgos naturales de un sujeto ahistórico, sino como producto y expresión de una cultura concreta, la reivindicación de la igualdad material y el respeto por las diferencias están más que justificadas en las sociedades periféricas y semiperiféricas contemporáneas.

La consolidación de las nuevas formas de entender la igualdad se ha logrado mediante su reconocimiento jurídico, al ser incorporadas en los textos constitucionales actuales de esas sociedades. Este hecho significa un apoyo institucional a las críticas contra la igualdad formal, delineadas en este trabajo. Pero en esas constituciones también se encuentra el valor de la igualdad ante la ley. No se trata como en la libertad y autonomía negativas, de nociones que usurpan el lugar de la libertad y autonomía genéricas; se trata de una noción que en sí misma es formal y cuya formalidad le permitió mejorar la situación de algunos de los sectores excluidos social y políticamente, en los inicios de la modernidad. La igualdad formal es un avance, en una cultura que aceptó por muchos siglos la «desigualdad natural» entre los hombres y entre hombres y mujeres. Todas las formas de desigualdad, desde la esclavitud hasta la exclusión social y económica, debían reproducirse por las normas jurídicas y las decisiones políticas dadas en un marco social determinado.

La conquista de la igualdad ante la ley sirvió para eliminar la separación entre poseedores y no poseedores de ciudadanía y privó de legitimidad a la práctica de usar las diferencias de condición biológica, social y económica como criterios de discriminación para el ejercicio de cargos y funciones públicas y para el disfrute de potestades y garantías ciudadanas. Es cierto que las constituciones y las declaraciones de derechos modernas no contemplaron la desaparición de todas las formas de discriminación; las mujeres, los no propietarios, los discapacitados, continuaron por fuera de la protección que garantizaba la igualdad formal. Pero a pesar de sus limitaciones, esas declaraciones significaron una ampliación importante de la categoría de ciudadano, como primer paso en la larga búsqueda de la igualdad real o material. Los privilegios de nacimiento se reemplazaron por aquellos derivados del propio esfuerzo y talento, lo que permitió el ascenso social de personas de origen humilde, modificándose así la estructura social jerárquica y estática, propia del mundo antiguo y medieval.

La igualdad jurídica es un pilar fundamental para la defensa de los derechos de las personas. Su carácter formal a la postre frenó lo que estaba implícito en ella como demanda individual y social: la denuncia de la marginalidad económica, social y cultural padecida por sectores importantes de la población. 


\section{La seguridad jurídica como valor básico.}

La ley general, impersonal y abstracta garantiza el abandono de la regulación de situaciones concretas, la resolución de conflictos determinada por la condición social y económica de las partes y demás prácticas asociadas a la casuística premoderna. El principio de legalidad asegura a los individuos un igual sometimiento de quienes detentan el poder político a las leyes que ellos mismos contribuyen a elaborar o elaboran. Estos elementos permiten la seguridad jurídica, entendida como la certeza y previsibilidad sobre la solución que se dará a los conflictos de intereses que lleguen a presentarse en el ámbito social. Al mismo tiempo, posibilitan el conocimiento previo de los derechos de que puede disfrutar todo ciudadano en el cuerpo político.

Una objeción a esta concepción tradicional de seguridad señala su capacidad de permanecer intacta ante la validez de leyes con un contenido abiertamente injusto ${ }^{21}$. La crítica, que se formula desde las teorías jurídicas contemporáneas, apunta a la necesidad de repensar este valor jurídico, porque mediante él se reproduce la indiferencia a las condiciones materiales de pobreza y marginalidad dadas en la sociedad. La certeza de que en la resolución de conflictos se aplicarán leyes violatorias de los derechos fundamentales, no puede ser el tipo de seguridad propio de una sociedad moderna, comprometida con la eliminación o reducción de los riesgos económicos y sociales. El Estado social de derecho, en tanto forma estatal comprometida con derechos prestacionales, es incompatible con una seguridad puramente formal. Esta situación sugiere la relevancia de reformular el concepto tradicional de seguridad jurídica. Los elementos más comunes de esa reformulación serían el reemplazo de la justicia intrínseca de cualquier ley o decisión judicial - al provenir del poder político - por leyes y decisiones judiciales que consulten la equidad, es decir que permitan la realización de la justicia en los casos concretos. La previsibilidad no vendría dada únicamente por el conocimiento del texto de las normas formalmente válidas, sino por las decisiones tomadas en casos similares por los tribunales y por los principios y derechos contenidos en las constituciones políticas. Los precedentes judiciales, en especial aquellos creados por los tribunales constitucionales, serían prescripciones morales que se incorporan a los ordenamientos jurídicos y sirven de criterio para la interpretación del resto de normas que los componen.

$\mathrm{Al}$ igual que acontece con la igualdad formal, la seguridad jurídica en su versión formal es un elemento definitorio del Estado de derecho. Su existencia implica un progreso moral con relación a la incertidumbre propia del Estado despótico premoderno, en la medida en que garantiza el sometimiento

\footnotetext{
${ }^{21}$ Betegón y otros, Lecciones de teoría del Derecho, McGrawHill, Madrid, 1997, pp. 28 y 29.
} 
del poder político al imperio de las leyes que él mismo promulga. Además, incluso las leyes más injustas cumplían una función orientativa de la actuación ciudadana. La garantía de los derechos sociales, económicos y culturales produce el tránsito de una seguridad formal, fundada en la injusticia del derecho, a una seguridad jurídica con contenido material. Esta nueva forma de seguridad no es más que la certeza sobre la existencia de normas respetuosas de todos los derechos fundamentales y la previsibilidad sobre la realización de una interpretación legal acorde a ese respeto.

\section{Algunas respuestas a las críticas consecuencialistas contra la justicia social.}

El Estado social de derecho al asumir la defensa y promoción de los derechos sociales, económicos y culturales de los ciudadanos, es un Estado que defiende y promueve una noción de justicia basada en los derechos. La justificación moral de esos derechos, definitorios del Estado, no debe prescindir de una evaluación, aunque breve, de sus posibles consecuencias. El ejercicio de dar razones morales debe integrar al análisis de los principios, la consideración de las consecuencias que se derivan de su aplicación ${ }^{22}$.

Acerca de la excesiva burocratización del Estado.

Es el argumento utilizado por quienes consideran que la búsqueda del bienestar material de los asociados genera un crecimiento desmedido del Estado y una determinación irracional de sus funciones. De hecho, en los Estados contemporáneos se ensayan nuevas posibilidades de atender las demandas ciudadanas por derechos sociales, sin que se produzca un indeseable incremento del aparato burocrático. En algunos países como Argentina o Colombia se ha ensayado una nueva forma de atender las necesidades básicas de los ciudadanos mediante la imposición del deber de solidaridad a los particulares. Obviamente este deber tiene como límite la autonomía individual, lo que significa que el Estado se ve obligado a compensar económicamente los servicios prestados. Esta forma de asumir su responsabilidad con las necesidades básicas de los ciudadanos ha resultado muy útil en algunas

${ }^{22}$ Ver Sen, Amartya, «Propiedad y Hambre» en Precedente Anuario jurídico No. 1, Centro de Investigaciones Jurídicas Precedente, U. Icesi, Cali, 2001， p. 99. Sobre este aspecto ha señalado A. Sen lo siguiente: «La aceptación de la importancia intrínseca de algún derecho no es garantía de que su evaluación moral global haya de ser favorable.... ninguna evaluación moral de un derecho puede prescindir de la consideración de sus consecuencias probables. No se puede eludir la necesidad de evaluaciones empíricas de los efectos de la aceptación de un derecho Los argumentos empíricos son absolutamente centrales en la filosofía moral». 
áreas como las de salud y educación. En ciertas ocasiones el Estado no puede brindar una prestación determinada y en lugar de sustentar el incumplimiento de su responsabilidad en la «ausencia de un aparato», busca mecanismos alternos como el señalado. Estas posibilidades, a las cuales se acude cada vez más, servirían para desmentir la concatenación necesaria entre la ampliación de los derechos sociales y el incremento de la burocracia estatal. Una implementación cuidadosa de la autonomía y de los derechos de las personas a quienes se demanda la prestación, garantiza la permanencia dentro de un Estado social de derecho y no un Estado social arbitrario.

El argumento de la ineficiencia económica.

El peso de este argumento disminuye si se considera la tendencia cada vez mayor a flexibilizar las relaciones laborales, crear normas de reestructuración empresarial, estimular la inversión extranjera y establecer estímulos tributarios. Estas políticas suelen ser apoyadas por organismos como el BID o el Fondo Monetario y en general son acatadas por los directores de la política macroeconómica en las sociedades periféricas y semiperiféricas. Además, en muchos casos se acepta que las condiciones de pobreza y marginalidad en que viven amplios sectores de la población contribuyen al incremento del crimen organizado, situación que torna insegura la actividad productiva privada. Los costos económicos impuestos por la satisfacción de las demandas ciudadanas pueden ser comparativamente inferiores a los costos de seguridad en que incurren los países con gran inestabilidad social. En la mayoría de los casos dramáticos, los mismos empresarios han manifestado su voluntad de contribuir a la modificación de las condiciones que impiden el desarrollo de cualquier actividad productiva, con la condición de que se obtengan resultados. La redistribución según necesidades, propia del Estado social de derecho, puede en el mediano y largo plazo contribuir a la reactivación económica. En algunos contextos casi podría afirmarse que sin una redistribución en los términos descritos no será posible reactivación alguna.

\section{La corrupción estatal.}

En general cualquier forma estatal, desde una visión realista, corre el riesgo de convivir con la corrupción. Los servicios de seguridad que presta el ente estatal, que para un anarquista libertario constituyen su única función legítima, no escapan a la acusación de corrupción, desgreño y demás prácticas socialmente indeseables. Este hecho serviría para justificar la deseabilidad de desaparición del Estado, incluso en su forma mínima. Sin embargo, el argumento parece vincular el fenómeno de la corrupción con el tamaño del Estado, en la medida en que parte de una premisa: a mayor tamaño, mayor corrupción. Esta relación podría explicarse por las posibilida- 
des de «esconder» los actos de corrupción en el ancho ámbito de funciones que el Estado desempeña. Pero el argumento se debilita si se considera que los organismos de control del Estado y la ciudadanía, a través de veedurías, pueden realizar un trabajo efectivo en la vigilancia del manejo de la propiedad pública. Las posibilidades y logros de este control no dependen exclusivamente del tamaño del aparato estatal. La cuestión también se vincula con una rama ejecutiva fuerte, que utiliza su facultad de disposición sobre los dineros del erario público para asegurarse la supremacía sobre las otras ramas del poder y sobre los ciudadanos. En algunos Estados, en especial en aquellos con tribunales constitucionales, se ha dado un desplazamiento de poder desde el aparato ejecutivo al judicial. No es extraño encontrar un poder judicial fuerte, que impone al gobierno la satisfacción de las necesidades materiales consideradas en el «mínimo vital» constitucionalmente protegido. Este fenómeno en la mayoría de los casos es catalogado como una distorsión del mecanismo democrático, debido al origen no popular de los jueces. La legitimidad de esta práctica, denominada «activismo judicial», vendría dada por el vínculo existente entre los derechos ciudadanos y la labor judicial. La razón de ser de esta labor ha sido desde sus orígenes la garantía efectiva y real de los derechos de los ciudadanos en un marco político determinado. Este punto trae numerosos problemas que no serán considerados aquí, pero sirve para ilustrar cómo la satisfacción de las demandas ciudadanas en material social, económica y cultural no necesariamente supone el fortalecimiento del poder ejecutivo.

El supuesto debilitamiento de la mediación estatal en los conflictos de intereses que se dan en la sociedad.

Según esta idea, un Estado que interviene a favor de una de las partes de un conflicto perdería la neutralidad necesaria para servir de árbitro. Sin embargo, el Estado hace mucho tiempo que dejó de ser el único árbitro en la solución de conflictos de intereses y no ha sido por dedicarse a cuestiones redistributivas. Este hecho se constata en el auge actual de los llamados «mecanismos alternativos de solución de conflictos» como el arbitramento, la amigable composición, la conciliación, etc. Sería absurdo señalar que es deseable el retorno a un tiempo en el cual sólo el Estado mediaba para obtener la solución pacífica de los desacuerdos dados en la Sociedad. La labor mediadora de los particulares cada vez gana más fuerza en materias comerciales, laborales y de familia. Las razones de su éxito son la celeridad, economía, y eficacia en la solución de las diferencias. Una labor de mediación estatal es necesaria y deseable, pero no se puede confundir a quienes reclaman derechos sociales con quienes solo reclaman el arbitraje. No hay razón para afirmar que el Estado tenga más responsabilidades con los segundos 
que con los primeros, en especial en aquellos contextos donde se ha demostrado que la incapacidad económica excluye a un número significativo de ciudadanos de los servicios estatales de justicia.

La subordinación de las asociaciones propias de la sociedad civil al aparato del Estado.

Es otro de los argumentos utilizados para intentar desestimar el compromiso estatal con la justicia social. De acuerdo con esta línea argumentativa, la dependencia que genera la inclusión de prácticas redistributivas en el listado de funciones del Estado social de derecho torna a los ciudadanos en meros receptores de la dádiva estatal y en espectadores de los procesos políticos. Este argumento puede haber sido válido para el Estado de bienestar, pero carece de fuerza para atacar al Estado social de derecho. Tal como he señalado líneas arriba, en un Estado de este tipo, las asociaciones asumen la tarea de canalizar las necesidades materiales y espirituales más sentidas de los ciudadanos. La respuesta institucional a estos reclamos es la consagración, promoción y defensa de derechos sociales, económicos y culturales - definitorios del Estado social -. También se puede afirmar que la consagración constitucional de la fórmula ha sido el resultado de presiones de distintos movimientos sociales, cansados de la marginalidad social, económica, política y cultural reproducida bajo la vigencia del Estado de derecho. La participación ciudadana no sólo es un derecho político fundamental que no requiere ser recortado para el logro de la justicia social; también es la condición misma de posibilidad de dicha justicia

La apelación al valor incondicionado de los individuos.

Desde cierta interpretación del principio liberal de dignidad humana, se podría decir que el Estado social de derecho no entrega nada como dádiva a los ciudadanos, es decir no vulnera su dignidad. Por el contrario, les reconoce nuevos derechos, como resultado de procesos de luchas sociales. Los colectivos que han presionado por la obtención de la igualdad material, asumieron en algún momento de su actuar político el valor prioritario del principio de dignidad humana y el vínculo de este principio con el de autonomía individual. Incluso se podría afirmar que quienes así actuaron llevaron hacia sus consecuencias más lógicas la consagración formal de los principios de igualdad y dignidad humanas. La dignidad hoy en día se concibe como una propiedad de los sujetos de necesidades y no sólo como el valor de un sujeto abstracto y racional. A este proceso del principio de dignidad alude el reconocimiento cada vez mayor de un «derecho a una vida digna», entendido como la posibilidad de disfrutar de condiciones materiales mínimas para el despliegue individual. 


\section{Razones morales para la redistribución estatal.}

En los Estados constitucionales se cristalizan las necesidades materiales básicas de las personas, como criterio de redistribución. No se trata de lo que individualmente se esgrime como «necesario» sino de aquellas necesidades que han logrado obtener reconocimiento jurídico mediante su consagración como derechos sociales, económicos y culturales. Estos derechos, al ser prestacionales, requieren de una redistribución de los bienes y de las cargas sociales por parte del Estado. Una vez concretados como normas jurídicas, su doble rango de derechos morales y jurídicos impone al Estado y a los particulares deberes concretos de protección y promoción, dentro de ciertos límites impuestos por el valor de la libertad y autonomía individuales.

El carácter moral de esos derechos prestacionales puede fundarse en el reconocimiento de los sujetos de necesidades, en oposición al carácter abstracto de los sujetos en las formulaciones liberales clásicas y libertarias. Se trata del reconocimiento entendido como sensibilidad ante las carencias materiales de los demás miembros del cuerpo político. A las carencias o necesidades materiales se les objeta que constituyen un límite demasiado inferior de la moral ${ }^{23}$ sin embargo, es posible que en sociedades periféricas - la latinoamericana en particular - la pobreza material se encuentre tan extendida, que este límite sea un punto inicial de redistribución legítimo.

El reclamo al Estado para que asuma un compromiso real con la justicia social basada en derechos se puede realizar ante el poder ejecutivo - como ocurre en un Estado de bienestar - ante el poder legislativo y/o el poder judicial. Actualmente en gran parte de las democracias constitucionales de los países periféricos y semiperiféricos, los ciudadanos privilegian la última vía. A ésta se le objeta el promover la intromisión de los jueces constitucionales - quienes garantizan los derechos mediante sus providencias - en asuntos de resorte del poder ejecutivo o legislativo ${ }^{24}$. Más allá de este debate jurídico por el poder, tiene sentido reconocer que precisamente estos cambios son el resultado inevitable de un Estado social de Derecho. Este hecho fue aceptado por la Corte Constitucional colombiana, al afirmar que « los acontecimientos de los últimos años han producido no sólo una

\footnotetext{
${ }^{23}$ Vázquez, Rodolfo, pp. 38 y 39.

${ }^{24}$ Ver Uprimny, Rodrigo, «legitimidad y conveniencia del control constitucional a la economía», en Precedente Anuario Jurídico 2001, Facultad de Derecho y Humanidades, Universidad Icesi, Cali, 2001, p. 60. Sobre este tema se afirma: «conforme a los pactos internacionales, la Constitución y la doctrina más autorizada, la obligación que tiene el Estado, y en especial 1 Legislador y el Ejecutivo, de asegurar la vigencia de los derechos sociales, debido precisamente a su carácter prestacional, no es idéntica a los deberes que tiene el Estado en relación con los derechos civiles y políticos. Por ello, estos textos señalan que esos derechos no son de aplicación inmediata integral sino de «realización progresiva», pues su satisfacción depende de la disponibilidad de recursos».
} 
transformación cuantitativa debida al aumento de la creación jurídica, sino también un cambio cualitativo, debido al surgimiento de una nueva manera de interpretar el derecho» ${ }^{25}$. Es importante recordar que el derecho es una expresión del poder de ese Estado. El derecho deja de ser un instrumento para mantener el statu-quo y asume una función redistributiva o promocional.

Las mayores resistencias a los derechos sociales se encuentran ligadas a su carácter prestacional. En este sentido se acusa al Estado que los garantiza de profundizar la ineficiencia económica ${ }^{26}$ y frenar el dinamismo de los movimientos sociales. El primer aspecto sería más dramático en sociedades de recursos escasos y demasiadas necesidades materiales insatisfechas. Este argumento, aunque importante, podría justificar la eliminación de cualquiera de las funciones que se atribuyen al Estado democrático moderno: el control social, la organización social, la resolución de conflictos, etc. Además los propios derechos civiles y políticos imponen al cuerpo político unos costos inevitables. La ineficiencia económica obliga a pensar en términos costo beneficio la garantía de los derechos, pero mediante una estimación real de los beneficios obtenidos con el mejoramiento de las condiciones materiales de vida de las personas.

El supuesto del «freno» a la iniciativa ciudadana descuida el origen de los derechos sociales, económicos y culturales. Su consagración positiva es precisamente el resultado de luchas dadas durante siglos por los diversos movimientos sociales marginados o excluidos. No son una dádiva estatal, sino una conquista social y su efectividad depende de la participación de las personas en las decisiones que las afectan y de la preocupación solidaria por la garantía de los derechos de los demás. En este sentido ha señalado Rodrigo Uprimny que la realización judicial de los derechos es sólo un componente de luchas sociales más amplias ${ }^{27}$.

La redistribución fundada en los derechos no riñe con los principios que el Estado de derecho dejó como legado a las sociedades occidentales contemporáneas: la legalidad y sus valores fundantes. Estos quedan resguardados frente a las pretensiones totalitarias del aparato estatal o de las mayorías ciudadanas. Las necesidades materiales y espirituales reconocidas jurídicamente aseguran un grado de atención mayor y su satisfacción no solo pasa por los canales institucionales; también requiere de nuevas estrategias como la acción conjunta entre grupos sociales, instituciones estatales y organismos internacionales. Los últimos, en especial los dedicados a la protección

\footnotetext{
${ }^{25}$ Sentencia T-402/92 Mag. Ponente Ciro Angarita Barón.

${ }^{26}$ Sobre este tema se puede consultar el texto de Hugo Palacios Mejía, «El control constitucional en el trópico», en Precedente, Anuario Jurídico, 2001, p. 7.

${ }^{27}$ Uprimny, ob.cit., p. 66.
} 
de derechos - tanto del orden regional como universal - empiezan cada vez más a atender las denuncias ciudadanas por violación de estos derechos. Hasta hace un par de décadas eran percibidos como derechos de realización progresiva y no como derechos fundamentales exigibles mediante recursos de amparo o denuncias internacionales.

Así como la redistribución de los medios materiales atañe directamente a la realización de los derechos de naturaleza económica, el reconocimiento sustenta o justifica moralmente los derechos sociales y culturales. El reconocimiento toma aquí otro sentido: se refiere al valor de los otros para la construcción de la propia identidad. La vida social hace que nos «reconozcamos» en los otros, en un proceso de autoconstrucción. Este hecho supone una distinción entre individualismo (conquista liberal) y egoísmo. Este último sería la exclusión de los demás en el propio interés, mientras que el primero puede entrañar una percepción «inclusiva» de los demás miembros del todo social. El reconocimiento es el respeto y promoción de aquellos rasgos de las personas, naturales o socialmente adquiridos, que constituyen su propia identidad. Las llamadas «acciones afirmativas» buscan que más allá de la tolerancia frente a lo diferente, se respeten y promuevan las diferencias consideradas valiosas para la vida privada y pública de las personas. En las sociedades latinoamericanas no se trata simplemente del reconocimiento de minorías étnicas y culturales, sino de grupos en ocasiones mayoritarios, tradicionalmente excluidos del derecho, que han obtenido inclusión constitucional a través de los derechos sociales y culturales. Esto se ha logrado mediante la participación activa de sus miembros.

El enfoque sobre las necesidades materiales - válido para ciertos sectores sociales - se coordina así con el enfoque sobre las capacidades para garantizar el ejercicio de una ciudadanía plena. El paso del individuo al ciudadano es un avance en la historia de los derechos humanos. La percepción de los miembros de la comunidad política como individuos consumidores hace inviable cualquier noción de reconocimiento. Este es relacional y supone unos sujetos morales - los ciudadanos - dotados de una sensibilidad moral mayor por los demás y por la vida pública. La ciudadanía se define como un estatuto formal de pertenencia a una comunidad política. Es una categoría multidimensional, como concepto legal, ideal político igualitario y referencia emocional en la que se recogen los derechos, las obligaciones y las lealtades de los individuos hacia una comunidad política dada ${ }^{28}$. Su definición depende del tipo de derechos que quedan comprendidos en ella. Sobre este punto Francisco Colom retoma los trabajos de Marshall, quien

\footnotetext{
${ }^{28}$ Colom, Francisco, «Los umbrales del demos: ciudadanos, transeúntes y metecos» en La filosofía política en perspectiva, Fernando Quesada (editor.), Anthropos, Barcelona 1998,
} 
clasificó las dimensiones civil, política y social de la ciudadanía. La primera recoge los derechos de la libertad individual, la segunda los derechos de participación, y la tercera los derechos sociales, económicos y culturales aunque el autor se refiere a los derechos que buscan dotar de unos mínimos de bienestar y de seguridad económica a las personas a fin de permitirles una vida digna -. El proceso es descrito como un proceso de inclusión, porque en una primera etapa de la ciudadanía los derechos sociales se encontraban separados de los derechos políticos y sólo estos determinaban la posesión de la ciudadanía. La ampliación de la noción de ciudadanía muestra uno de los mayores logros de los procesos sociales de lucha por el reconocimiento: la institucionalización del compromiso estatal y social con la provisión colectiva de los bienes necesarios para la participación en la vida pública, en condiciones de autonomía moral ${ }^{29}$. No basta con dejarle al Estado el papel de reordenar de manera solidaria la comunidad política. Es deseable que las asociaciones sociales asuman un compromiso social efectivo, de carácter supletivo o complementario, frente al papel corrector que realiza el Estado.

Cabe en fin anotar que la realización de los derechos sociales, económicos y culturales es una condición de posibilidad para la paz, por cuanto minimiza el impacto de las principales causas de conflictos sociales: la marginalidad, el hambre, y en general la ausencia de reconocimiento en todas sus modalidades. La paz a su vez es una condición de posibilidad para el disfrute de los derechos en general. Este círculo virtuoso ${ }^{30}$ sería una razón moral adicional para exigir al Estado un compromiso con la justicia basada en derechos. Las instituciones legitimadas por su justicia tienen más posibilidades de exigir obediencia a los ciudadanos. El derecho que cumple cabalmente su función de promover e impulsar el respeto de las diferentes clases de derechos asegura de mejor manera el acatamiento de sus disposiciones. Es quizá por esto que goza de un amplio prestigio la idea según la cual los ciudadanos tienen un deber moral de obedecer al derecho justo. Cuando el Estado productor del derecho y sus órganos realizan la justicia, se ha escogido un camino un poco más seguro hacia la paz.

\footnotetext{
${ }^{29}$ Ver Colom, ob.cit., p. 44.

${ }^{30}$ Ver Papacchini, Angelo, Los derechos humanos, un desafío a la violencia, Altamir ediciones, Bogotá, 1997, p. 392 a 397.
} 
Bibliografía:

Berlin, Isaiah, Cuatro ensayos sobre la libertad, Alianza, Madrid, 1996.

Betegón, Jerónimo y otros, Lecciones de teoría del Derecho, McGrawHill, Madrid, 1997.

Colom, Francisco, «Los umbrales del demos: ciudadanos, transeúntes y metecos» en La filosofía política en perspectiva, Fernando Quesada (editor.), Anthropos, Barcelona 1998.

Forsthoff, Ernst, «Concepto y esencia del Estado social de derecho», en El Estado social Wolfgang Abendroth, Ernst Forsthoff y Karl Doehring, Centro de estudios constitucionales, Madrid, 1986.

Fraser, Nancy, «Redistribución y reconocimiento: hacia una visión integrada de justicia del género» en Revista Internacional de Filosofía Política No. 8, UNEM y UAM, Madrid, 1996.

Grueso, Delfín, «Liberalismo, comunitarismo y los problemas de la justicia social» en Práxis filosófica Nueva Serie, No. 5 Octubre de 1995.

Hayek, Federik, Los fundamentos de la libertad, Ed. Folio, Barcelona, 1997.

Hegel, George, W., Filosofía del Derecho, Editorial Sudamericana, Buenos Aires, 1.975

Macpherson, C.b., La teoría política del individualismo posesivo, De. Fontanella S.A., Barcel. 1.979

Nozick, Robert, Anarquía, Estado y Utopía, F.C.E., México D.F., 1.988

Papacchini, Angelo, Los derechos humanos un desafío a la violencia, Altamir Ediciones, Bogotá, 1997.

_, «El porvenir de la ética. La autonomía moral, un valor imprescindible para nuestro tiempo», Revista de Estudios sociales No. 5. Enero 2000.

Peces Barba, Gregorio, Introducción a la Filosofía del Derecho, Madrid, Debate, 1994.

Rorty, Richard, Contingency, irony, and solidarity, Cambridge University Press, Cambridge, 1989.

Sandel, Michael, Liberalism and the limits of Justice, Cambridge University Press, 1.982.

Sen, Amartya, Desarrollo y libertad, Planeta, Bogotá 2000.

, «Propiedad y Hambre» en Precedente Anuario jurídico No. 1, Centro de Investigaciones Jurídicas Precedente, U. Icesi, Cali, 2001.

Sennett, Richard, La corrosión del carácter, Anagrama, Barcelona, 2000.

Smith, Adam, La teoría de los sentimientos morales, Alianza Editorial S.A., Madrid, 1997. 
, Investigación sobre la naturaleza y causa de la riqueza de las naciones, F.C.E., México D.F., 1994.

Soriano, Ramón, «Las funciones sociales del derecho», Sociología del derecho, Ariel, Barcelona, 1997.

Sterba, James, Justice: Alternative Political perspectives, Wadsworth publishing company, Belmont, 1991.

Tushnet, Mark, «Ensayo sobre los derechos» en Sociología jurídica, editado por Mauricio García Villegas, editorial unilibros, Bogotá, 2001.

Uprimny, Rodrigo, «Legitimidad y conveniencia del control constitucional a la economía», en Precedente Anuario Jurídico 2001, Centro de Investigaciones Precedente, U. Icesi, Cali, 2001.

Vázquez, Rodolfo, Liberalismo, Estado de derecho y minorías, Paidós, México D.F, 2001. 